\begin{tabular}{ll|l}
\cline { 2 - 3 } & \multicolumn{3}{l}{ Intervent Neurol 2014;3:115-121 } \\
\cline { 2 - 3 } & $\begin{array}{l}\text { DOI: 10.1159/000375540 2015 S. Karger AG, Basel } \\
\text { Published online: March 13, } 2015\end{array}$ & $\begin{array}{l}\text { (c) } \\
\text { 1664-9737/15/0034-0115 } \$ 39.50 / 0 \\
\text { www.karger.com/ine }\end{array}$ \\
\hline
\end{tabular}

\title{
Endovascular Treatment for Acute Ischemic Stroke: Considerations from Recent Randomized Trials
}

\author{
Manabu Shirakawa ${ }^{a}$ Shinichi Yoshimura ${ }^{a}$ Kiyofumi Yamada ${ }^{b}$ \\ Kazutaka Uchida ${ }^{\text {a }}$ Seigo Shindou ${ }^{\text {a }}$ \\ a Department of Neurosurgery, Hyogo College of Medicine, Nishinomiya, and \\ ${ }^{b}$ Department of Neurosurgery, Sato Daiichi Hospital, Usa, Japan
}

\section{Key Words}

Acute ischemic stroke $\cdot$ Clot retriever . Tissue plasminogen activator - Randomized trial

\begin{abstract}
Background: Despite increasing use of intravenous recombinant tissue plasminogen activator therapy, the large number of patients ineligible for treatment or for whom treatment is ineffective has become problematic. Summary: The number of endovascular treatments for acute ischemic stroke is increasing each year. This treatment provides higher recanalization rates for occluded vessels but may lead to hemorrhagic complications such as subarachnoid hemorrhage. Results were announced for three randomized controlled trials in 2013, with all failing to show the superiority of endovascular treatment. These results have had a major negative impact, but a new randomized controlled trial, the Multicenter Randomized CLinical trial of Endovascular treatment for Acute ischemic stroke in the Netherlands (MR CLEAN), showed that acute endovascular treatment was superior to standard medical treatment in terms of clinical outcomes. With this positive result, interim analyses from other randomized trials appear likely to show the effectiveness of endovascular treatment. Key Message: Clinical evidence of acute stroke intervention using mechanical devices might be established in the near future.

(C) 2015 S. Karger AG, Basel
\end{abstract}

\section{Introduction}

Intravenous recombinant tissue plasminogen activator therapy (IV rt-PA) for acute ischemic stroke has become widespread around the world. However, despite this increasing use of IV rt-PA, the large number of patients ineligible for treatment or for whom treatment 
proves ineffective has become problematic. Clinical trials have therefore been undertaken to clarify the effectiveness of intra-arterial rt-PA, but benefits have not been confirmed compared to IV rt-PA alone [1]. Endovascular treatments (EVTs) such as mechanical thrombectomy have thus been regarded as rescue therapy for IV rt-PA-failed or -ineligible patients.

Three recent randomized controlled trials (RCTs) evaluated EVT in acute ischemic stroke [2-4], but all have failed to show the efficacy of EVT. However, a new RCT, the Multicenter Randomized CLinical trial of Endovascular treatment for Acute ischemic stroke in the Netherlands (MR CLEAN), was the first to show that acute EVT was effective in achieving better clinical outcomes for patients with anterior circulation [5]. This article reviews these RCTs and discusses future directions in EVT for acute ischemic stroke.

\section{Advantages and Disadvantages of IV rt-PA}

Clinical evidence of IV rt-PA is well established, and there is no need for catheter techniques. This treatment has therefore become widespread around the world within a short period. However, a large number of patients are ineligible for treatment due to time restrictions. Based on the results of an RCT [6], eligibility for IV rt-PA was extended to $4.5 \mathrm{~h}$ after stroke onset. While this has reduced the number of patients ineligible due to time constraints, less than $5 \%$ of patients presenting with acute ischemic stroke prove eligible for IV rt-PA.

Another problem with IV rt-PA is the large number of patients for whom treatment is ineffective. Efficacy rates are particularly low for major arterial occlusions involving vessels such as the internal carotid artery, the proximal portion of the middle cerebral artery or the basilar artery $[7,8]$. In particular, favorable outcome rates in patients with internal carotid artery occlusion have been reported to be only $10-20 \%$. One reason for such poor outcomes in patients with a major arterial occlusion is failed recanalization of the occluded vessel, probably due to the existence of large thrombi or underlying stenosis of the artery when the diameter of the occluded vessel is large.

\section{Evolvement of Clot Retrieval Devices}

\section{The Merci ${ }^{\circledR}$ Retriever}

Acute ischemic stroke has conventionally been treated with local fibrinolytic therapies, such as using urokinase, but 2010 marked the start of a new era of catheter therapy with the approval of the Merci Retriever (Stryker, San Jose, Calif., USA). This treatment is indicated within $8 \mathrm{~h}$ of stroke onset in patients with major cerebral arterial occlusion or in those ineligible for IV rt-PA or for whom IV rt-PA has proven ineffective. The device is deployed distal to the thrombus, engaging and retrieving the thrombus with the coil-shaped loop at the tip. In the Multi MERCI Trial, a prospective study conducted in the United States, the rate of successful recanalization [thrombolysis in myocardial infarction (TIMI) flow grade 2-3] was $68 \%$, and the favorable outcome rate after 90 days [modified Rankin scale (mRS) 0-2] was $36 \%$ [9]. However, the Merci Retriever has also been associated with bleeding complications. Independent predictors of bleeding when using the Merci Retriever have been identified as hypertension, distal M1 portion occlusion, rescue angioplasty, and vessel perforation [10].

The Penumbra System ${ }^{\circledR}$

The Penumbra System (Penumbra, Alameda, Calif., USA) was approved in 2011, and achieves recanalization by aspirating the thrombus. In a prospective study using this device, the recanalization rate (TIMI $2-3$ ) was $82 \%$, and the favorable outcome rate (mRS $0-2$ ) was 
Table 1. Devices and clinical results of EVT

\begin{tabular}{|c|c|c|c|c|c|c|}
\hline \multirow[b]{2}{*}{ Used device } & \multirow{2}{*}{$\begin{array}{l}\text { Multi MERCI Trial } \\
(\mathrm{n}=164) \\
\text { Merci }\end{array}$} & \multirow{2}{*}{$\begin{array}{l}\text { Penumbra Pivotal } \\
\text { Stroke Trial }(n=125) \\
\text { Penumbra }\end{array}$} & \multicolumn{2}{|l|}{ SWIFT } & \multicolumn{2}{|l|}{ Trevo 2} \\
\hline & & & $\begin{array}{l}\text { Solitaire } \\
(n=58)\end{array}$ & $\begin{array}{l}\text { Merci } \\
(n=55)\end{array}$ & $\begin{array}{l}\text { Trevo } \\
(n=88)\end{array}$ & $\begin{array}{l}\text { Merci } \\
(n=90)\end{array}$ \\
\hline Recanalization (TIMI) & $68 \%$ & $81.6 \%$ & $89 \%$ & $67 \%$ & $92 \%$ & $77 \%$ \\
\hline Procedure-related complication & $9.8 \%$ & $12.8 \%$ & $14 \%$ & $16 \%$ & $15 \%$ & $23 \%$ \\
\hline Symptomatic intracranial hemorrhage & $9.8 \%$ & $11.2 \%$ & $2 \%$ & $11 \%$ & $7 \%$ & $9 \%$ \\
\hline Favorable outcome (mRS $0-2)$ & $36 \%$ & $25 \%$ & $58 \% *$ & $33 \% *$ & $40 \%$ & $22 \%$ \\
\hline
\end{tabular}

* Swift defined favorable outcome as an mRS of $\leq 2$ or equal to the prestroke mRS if the prestroke mRS was $>2$, or NIHSS score improvement of $\geq 10$ points, and neurological condition at 90 days, including NIHSS, Barthel index, and mRS.

$25 \%$ [11]. Favorable findings on computed tomography at baseline and recanalization within $5 \mathrm{~h}$ have been reported as good prognostic factors [12].

The size of the device must be carefully selected to match the vessel. The smaller the difference in size between the target vessel and the reperfusion catheter tip, the greater the aspiration force, meaning that peripheral embolization will be less likely to occur. In a clinical study using the large-diameter Penumbra 054 catheter (SPEED trial) [13], the median time required for thrombus aspiration was $18 \mathrm{~min}$, significantly shorter than the $45 \mathrm{~min}$ reported with a conventional system, and the recanalization rate (TIMI 2-3) was 92\%. More recently, a larger-diameter series has become available, and treatment outcomes are expected to improve further. Moreover, the rate of subarachnoid hemorrhage immediately after treatment with the Penumbra System is low.

\section{Stent-Like Clot Retrieval Devices}

The most promising devices on the horizon are currently stent-like clot retrievers. These devices temporarily deploy a stent to the occlusion site, and the thrombus along the whole length of the stent is retrieved. A RCT has already been conducted in the United States, demonstrating the superiority of the Merci Retriever [14, 15]. These new devices are promising because they achieve higher recanalization rates while requiring shorter procedure times. Devices such as Solitaire ${ }^{\mathrm{TM}}$ (Covidien, Irvine, Calif., USA) and Trevo ${ }^{\mathrm{TM}}$ (Stryker) are expected to become mainstream treatment options.

The results of multicenter, prospective RCTs between Solitaire and Merci (SWIFT trial) [14] and between Trevo and Merci (Trevo 2 trial) [15] are summarized in table 1 . These stentlike clot retrieval devices offering higher recanalization rates and shortened procedure times represent a new era of 'second-generation' devices. Expedited approval of these devices is also expected.

\section{Results of RCTs}

The results of three RCTs on EVT in acute ischemic stroke were announced at the 2013 International Stroke Conference held in Honolulu, Hawaii, USA. These were the IMS-III study [2] to evaluate the effectiveness of EVT in addition to IV rt-PA, the MR-RESCUE study [3] to evaluate the effectiveness of EVT based on imaging diagnosis, and the SYNTHESIS Expansion study [4] that compared IV rt-PA and EVT (table 2). We will now discuss the results of each study. 

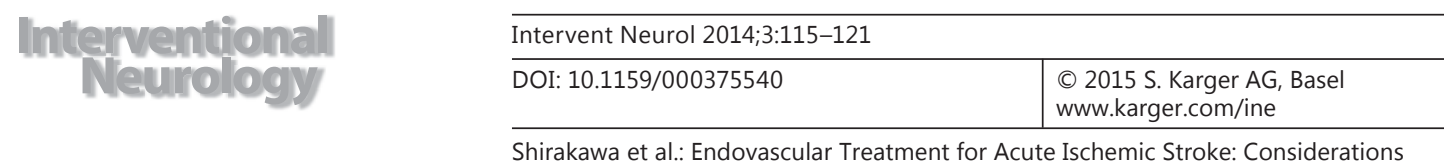

Shirakawa et al.: Endovascular Treatment for Acute Ischemic Stroke: Considerations from Recent Randomized Trials

Table 2. Summary of 3 recent RCTs regarding EVT for acute stroke

\begin{tabular}{|c|c|c|c|c|c|c|c|c|c|}
\hline & \multicolumn{3}{|l|}{ IMS-III } & \multicolumn{3}{|l|}{ MR-RESCUE } & \multicolumn{3}{|c|}{ SYNTHESIS Expansion } \\
\hline & EVT & $\begin{array}{l}\text { IV rt-PA } \\
\text { only }\end{array}$ & $\mathrm{p}$ & $\begin{array}{l}\text { EVT, } \\
\text { penumbral }\end{array}$ & $\begin{array}{l}\text { standard } \\
\text { care, } \\
\text { penumbral }\end{array}$ & $\mathrm{p}$ & EVT & $\begin{array}{l}\text { IV rt-PA } \\
\text { only }\end{array}$ & $\mathrm{p}$ \\
\hline Patients & 434 & 222 & & 34 & 34 & & 181 & 181 & \\
\hline Favorable outcome* & $40.8 \%$ & $38.7 \%$ & 0.25 & $21.0 \%$ & $26.0 \%$ & 0.48 & $30.4 \%$ & $34.8 \%$ & 0.37 \\
\hline Mortality & $19.1 \%$ & $21.6 \%$ & 0.52 & $18.0 \%$ & $21.0 \%$ & 0.75 & $14.4 \%$ & $9.9 \%$ & 0.22 \\
\hline Symptomatic ICH & $6.2 \%$ & $5.9 \%$ & 0.83 & $9.0 \%$ & $6.0 \%$ & 0.24 & $6 \%$ & $6 \%$ & 0.99 \\
\hline
\end{tabular}

* mRS 0-2 in IMS-III and MR-RESCUE and 0-1 in SYNTHESIS Expansion. ICH = Intracranial hemorrhage.

IMS-III

IMS-III [2] was a multicenter, collaborative, randomized study to evaluate the additional effectiveness of EVT in addition to IV rt-PA. Patients were assigned in a 2:1 ratio to an additional EVT group and an IV rt-PA-alone group. The primary endpoint was mRS 0-2 at 90 days.

The study was expected to enroll 900 patients but was stopped early because no additional effectiveness was shown by the time 656 patients had been accumulated. No significant difference in primary endpoint was noted (EVT, 40.8\%; rt-PA alone, 38.8\%). Even in a subgroup analysis after stratification for National Institutes of Health Stroke Scale (NIHSS) score (NIHSS score 8-19 vs. $\geq 20$ ), there was still no significant difference. Furthermore, no significant differences were evident in mortality after 90 days $(19.1 \mathrm{vs.} 21.6 \%, \mathrm{p}=0.52)$ or the rate of symptomatic intracranial hemorrhage after $30 \mathrm{~h}(6.2 \mathrm{vs.} 5.9 \%, \mathrm{p}=0.83)$.

These results indicate no additional effectiveness of EVT. However, the IMS-III study had the following limitations: (1) Major arterial occlusion was not confirmed in more than half of the enrolled patients. (2) The mean time from IV rt-PA to EVT was $\geq 2 \mathrm{~h}$. (3) The recanalization rate [thrombolysis in cerebral infarction (TICI) flow grade $2 \mathrm{~b}-3$ ] with EVT was low, at only about $40 \%$.

Based on the above results, EVT should target major cerebral arterial occlusions. In addition, to achieve higher recanalization rates and shorten the time to recanalization, future trials are likely to mainly use stent-like retrieval devices.

\section{MR-RESCUE}

In the MR-RESCUE study [3], patients within $8 \mathrm{~h}$ of stroke onset who had major cerebral arterial occlusion (anterior circulation only) were randomly assigned to receive endovascular or standard treatment, and imaging of the penumbra region was performed in each patient. The purpose of the study was to evaluate whether EVT was more effective in patients with a larger penumbra. Outcomes were assessed using the 90-day mRS.

The results showed no difference in mean 90-day mRS score, which was 3.9 in both groups. Moreover, EVT was no more effective, irrespective of the presence or absence of a penumbra pattern. However, this study also showed the following limitations: (1) The mean time from stroke onset to initiation of EVT was $\geq 6 \mathrm{~h}$. (2) The recanalization rate (TICI 2b-3) with EVT was low, at only $27 \%$.

In this study, unlike in the IMS-III study, major arterial occlusion was confirmed by magnetic resonance angiography before randomization, using a protocol similar to that applied clinically in Japan. However, because of the long time until initiation of EVT and the very low recanalization rate, no effectiveness was demonstrated. 
Table 3. Some ongoing RCTs

\begin{tabular}{|c|c|c|c|c|}
\hline & $\begin{array}{l}\text { Aim of } \\
\text { enrollment }\end{array}$ & Subjects & Primary endpoint & Secondary endpoint \\
\hline $\begin{array}{l}\text { Swift } \\
\text { prime }\end{array}$ & 833 & $\begin{array}{l}\text { To patients within } 6 \text { h of onset; } \\
\text { IV rt-PA vs. IV rt-PA + EVT } \\
\text { (Solitaire FR only) }\end{array}$ & $\begin{array}{l}\text { mRS at } 90 \text { days assessed } \\
\text { via blind evaluation }\end{array}$ & $\begin{array}{l}\text { All-cause mortality ( } 90 \text { days); mRS } 0-2 \text { at } \\
90 \text { days; change in NIHSS at } 27 \pm 3 \mathrm{~h}\end{array}$ \\
\hline Therapy & 692 & $\begin{array}{l}\text { To patients eligible for IV rt-PA } \\
\text { and who have a large clot ( }>8 \\
\text { mm); IV rt-PA vs. IV rt-PA + } \\
\text { EVT (Penumbra System only) }\end{array}$ & $\begin{array}{l}\text { mRS } 0-2 \text { at } 90 \text { days } \\
\text { assessed via blind } \\
\text { evaluation; incidence of all } \\
\text { events }\end{array}$ & $\begin{array}{l}\text { Good outcome (NIHSS improvement } \geq 10 \text {, } \\
\text { NIHSS } 0-1 \text { or } m R S ~ 0-2 \text { at } 30 \text { days); } \\
\text { incidence of ICH }\end{array}$ \\
\hline Revascat & 690 & $\begin{array}{l}\text { To patients within } 8 \mathrm{~h} \text { of onset; } \\
\text { medical therapy versus } \\
\text { endovascular therapy } \\
\text { (Solitaire FR only) }\end{array}$ & $\begin{array}{l}\text { mRS at } 90 \text { days assessed } \\
\text { via blind evaluation }\end{array}$ & $\begin{array}{l}\text { Mortality at } 90 \text { days; sICH at } 24 \mathrm{~h} \text {; } \\
\text { infarct volume on CT at } 24 \text { h; vessel } \\
\text { recanalization at } 24 \mathrm{~h} \text {; complications } \\
\text { related in endovascular arm }\end{array}$ \\
\hline Positive & 750 & $\begin{array}{l}\text { To patients ineligible for IV } \\
\text { rt-PA within } 12 \text { h of onset; } \\
\text { medical therapy versus } \\
\text { endovascular therapy (any } \\
\text { device of } \\
\text { mechanical thrombectomy) }\end{array}$ & $\begin{array}{l}\text { Rate of good functional } \\
\text { outcome compared to } \\
\text { medical therapy at } 90 \text { days }\end{array}$ & $\begin{array}{l}\text { Global disability at } 90 \text { days; mortality at } \\
90 \text { days; proportion of patients with good } \\
\text { functional recovery at } 90 \text { days; ICH at } 90 \\
\text { days; procedure-related SAEs at } 90 \text { days; } \\
\text { good revascularization (TICI } 2 \text { b or } 3 \text { ) } \\
\text { following device use }\end{array}$ \\
\hline Dawn & 500 & $\begin{array}{l}\text { To patients } 6-24 \mathrm{~h} \text { after last } \\
\text { seen well; medical therapy } \\
\text { versus endovascular therapy } \\
\text { (Trevo only) }\end{array}$ & $\begin{array}{l}\text { Weighted mRS score; } \\
\text { stroke-related mortality }\end{array}$ & $\begin{array}{l}\text { Good functional outcome at } 90 \text { days; } \\
\text { mortality at } 90 \text { days; median final infarct } \\
\text { area at } 90 \text { days; sICH at } 90 \text { days; } \\
\text { procedure- and device-related SAEs at } 90 \\
\text { days; good revascularization rate (TICI } 2 b \\
\text { or 3) }\end{array}$ \\
\hline
\end{tabular}

$\mathrm{ICH}=$ Intracranial hemorrhage; $\mathrm{sICH}=$ symptomatic intracranial hemorrhage; $\mathrm{CT}$ = computed tomography; SAEs = severe adverse events.

\section{SYNTHESIS Expansion}

The SYNTHESIS Expansion study [4] randomized patients with acute ischemic stroke within $4.5 \mathrm{~h}$ of onset to undergo either EVT or IV rt-PA. The primary endpoint was defined as mRS $0-1$ after 3 months.

The results showed no significant differences between groups in terms of the proportion of patients with a good outcome of mRS 0-1 (EVT group, 30.4\%; IV rt-PA group, 34.8\%; p = $0.16)$. The rate of symptomatic intracranial hemorrhage was $6 \%$ in both groups. Time from onset until initiation of treatment was $3.75 \mathrm{~h}$ in the EVT group and $2.75 \mathrm{~h}$ in the IV rt-PA group $(\mathrm{p}<0.001)$. EVT was therefore performed $1 \mathrm{~h}$ later.

The major limitation in the SYNTHESIS Expansion study, as in the IMS-III study, was that major arterial occlusion was not confirmed before randomized assignment. Therefore, among the 181 patients in the EVT group, 165 actually received treatment. Among these, 109 received intra-arterial rt-PA, and 56 underwent mechanical thrombectomy. In other words, about $10 \%$ did not receive EVT after randomized assignment, and the modality in the two thirds of patients who did was intra-arterial rt-PA. Therefore, one would have to say that the design in this study was incomplete. The key message from this was that EVT mainly with intra-arterial rt-PA does not improve outcomes.

These results were announced at the 2013 International Stroke Conference and also published. However, all of these investigations showed flaws in the study design and methodology. We have therefore been waiting for the results of new comparison studies with stent retrievers and improved protocols. 


\section{MR CLEAN}

The MR CLEAN study [5] reported that intra-arterial treatment was effective and safe when given within $6 \mathrm{~h}$ of stroke onset for patients with acute ischemic stroke caused by an intracranial arterial anterior-circulation occlusion. In the study, 500 patients with acute ischemic stroke of the anterior circulation within $6 \mathrm{~h}$ of onset were randomized to intervention or control groups. Randomization was allowed when the intracranial occlusion had been established by computed tomography angiography, magnetic resonance angiography or digital-subtraction angiography. Patients with a NIHSS score $\geq 2$ were included. The primary outcome was mRS score at 90 days. Secondary outcomes were the imaging parameter of vessel recanalization at $24 \mathrm{~h}$ and final infarct volume calculation. In the intervention and control groups, the mean initial NIHSS scores were 17 and 18, and the times to randomization were 196 and $204 \mathrm{~min}$, respectively. EVT involved retrievable stents in $97 \%$ of cases. The time from onset to groin puncture was $260 \mathrm{~min}$. As results, the intervention group showed good outcomes at 90 days compared to the control group (mRS $\leq 2,32.6$ vs. $19.1 \%$ ), and the mean NIHSS score after 5-7 days was 2.9 points lower in the intervention group than in the control group. The intervention group showed parenchymal hemorrhage type 2 less frequently than the control group ( 6 vs. 5.2\%, respectively), and mortality rates within 30 days were almost the same in the two groups (18.9 vs. $18.4 \%$, respectively).

\section{Ongoing Trials}

Other studies regarding mechanical thrombectomy are currently ongoing. Among these, various large trials are summarized in table 3. SWIFT PRIME and REVASCAT were designed to clarify whether endovascular therapy is superior to IV rt-PA alone. REVASCAT, POSITIVE, and DAWN are aimed at extending the therapeutic time window in endovascular therapy for acute ischemic stroke. With the positive results from MR CLEAN, interim analyses from some of these studies appear likely to show the effectiveness of EVT.

\section{Conclusions}

In addition to MR CLEAN, other ongoing RCTs of EVT are expected to show the superiority of standard medical treatments. If clinical evidence can be established with positive results from RCTs, EVT will become a first-line treatment for acute ischemic stroke. The next issue might be how best to extend the indications of EVT for acute stroke.

\section{References}

1 IMS Study Investigators: Combined intravenous and intra-arterial recanalization for acute ischemic stroke: the Interventional Management of Stroke Study. Stroke 2004;35:904-911.

2 Broderick JP, Palesch YY, Demchuk AM, et al; Interventional Management of Stroke (IMS) III Investigators: Endovascular therapy after intravenous t-PA versus t-PA alone for stroke. N Engl J Med 2013;368:893-903.

3 Kidwell CS, Jahan R, Gornbein J, et al: A trial of imaging selection and endovascular treatment for ischemic stroke. N Engl J Med 2013;368:914-923.

4 Ciccone A, Valvassori L, Nichelatti M, et al: Endovascular treatment for acute ischemic stroke. N Engl J Med 2013;368:2433-2434.

5 Berkhemer OA, Fransen PS, Beumer D, et al; MR CLEAN Investigators: A randomized trial of intraarterial treatment for acute ischemic stroke. N Engl J Med 2015;372:11-20

6 Hacke W, Kaste M, Bluhmki E, et al: Thrombolysis with alteplase 3-4.5 h after acute ischemic stroke. $\mathrm{N}$ Engl J Med 2008;359:1317-1329.

7 Hirano T, Sasaki M, Mori E, et al: Residual vessel length on magnetic resonance angiography identifies poor responders to alteplase in acute middle cerebral artery occlusion patients: exploratory analysis of the Japan Alteplase Clinical Trial II. Stroke 2010;41:2828-2833. 
8 Yoshimura S, Sakai N, Okada Y, et al; Recovery by Endovascular Salvage for Cerebral Ultra-acute Embolism (RESCUE)-Japan Registry Investigators: Efficacy of endovascular treatment for acute cerebral large-vessel occlusion: analysis of nationwide prospective registry. J Stroke Cerebrovasc Dis 2014;23:1183-1190.

9 Smith WS, Sung G, Saver J, et al; Multi MERCI Investigators: Mechanical thrombectomy for acute ischemic stroke: final results of the Multi MERCI trial. Stroke 2008;39:1205-1212.

10 ShiZS, Liebeskind DS, Loh Y, etal; UCLA Endovascular Stroke Therapy Investigators: Predictors of subarachnoid hemorrhage in acute ischemic stroke with endovascular therapy. Stroke 2010;41:2775-2781.

11 Penumbra Pivotal Stroke Trial Investigators: The penumbra pivotal stroke trial: safety and effectiveness of a new generation of mechanical devices for clot removal in intracranial large vessel occlusive disease. Stroke 2009;40:2761-2768.

12 Goyal M, Menon BK, Coutts SB, et al; Penumbra Pivotal Stroke Trial Investigators, Calgary Stroke Program, and the Seaman MR Research Center: Effect of baseline CT scan appearance and time to recanalization on clinical outcomes in endovascular thrombectomy of acute ischemic strokes. Stroke 2011;42:93-97.

13 Frei D, Gerber J, Turk A, et al: The SPEED study: initial clinical evaluation of the Penumbra novel 054 Reperfusion Catheter. J Neurointerv Surg 2013;5(suppl 1):i74-i76.

14 Saver JL, Jahan R, Levy EI, et al; SWIFT Trialists: Solitaire flow restoration device versus the Merci Retriever in patients with acute ischaemic stroke (SWIFT): a randomised, parallel-group, non-inferiority trial. Lancet 2012;380:1241-1249.

15 Nogueira RG, Lutsep HL, Gupta R, et al; TREVO 2 Trialists: Trevo versus Merci retrievers for thrombectomy revascularisation of large vessel occlusions in acute ischaemic stroke (TREVO 2): a randomised trial. Lancet 2012;380:1231-1240 